\title{
EGU21-9856
}

https://doi.org/10.5194/egusphere-egu21-9856

EGU General Assembly 2021

(c) Author(s) 2021. This work is distributed under

the Creative Commons Attribution 4.0 License.

\section{Deformation structure and peak-metamorphic temperature in Kodiak accretionary complex, Alaska}

\author{
Kristijan Rajic ${ }^{1,2,3}$, Hugues Raimbourg ${ }^{1,3}$, Vincent Famin ${ }^{4}$, Donald Fisher ${ }^{5}$, and Kristin Morell ${ }^{6}$ \\ 1'Université d'Orléans, ISTO, UMR 7327, 45071 Orléans (kristijan.rajic@univ-orleans.fr) \\ ${ }^{2}$ CNRS, ISTO, UMR 7327, 45071 Orléans, France \\ ${ }^{3}$ BRGM, ISTO, UMR 7327, BP 36009, 45060 Orléans, France \\ ${ }^{4}$ Laboratoire Géosciences Réunion, Université de La Réunion, IPGP, Sorbonne Paris Cité, UMR 7154 CNRS, 7 Saint-Denis, La \\ Réunion, France \\ ${ }^{5}$ Department of Geosciences, Pennsylvania State University, University Park, PA 16801, USA \\ ${ }^{6}$ Department of Earth Science, University of California, Santa Barbara, Santa Barbara, CA 93106, USA
}

The Kodiak archipelago (Southwest Alaska) represents a well exposed paleo-accretionary prism with its modern equivalent to the modern Alaskan Trench further southeast. The complex consists of metasedimentary and magmatic rocks, whose age span from the Triassic-Jurassic units on the northwestern side of the archipelago towards the Miocene units on the southeast. The complex dominantly consists of trench sediments, in which the sedimentary stratification is still visible. In addition, two tectonic mélanges, composed of lenses of metabasites embedded in sheared metasediments, are intercalated between the coherent formations. We carried out an extensive field survey to describe the kinematics and temperature conditions of deformation across the whole subduction complex.

Mélange terrains are characterized by subduction-related deformation in the form of a pervasive network of top-to-the-trench shear zones. In contrast, we observed wider range of deformation geometries in coherent units: The Kodiak Landward belt is characterized by top-to-the-trench simple shear. In the Kodiak Central belt, strain geometry varies spatially from dominant top-to-thetrench simple shear to horizontal extension evidenced by conjugate sets of extensional shear bands. Further to southeast, the Kodiak Seaward belt and the Ghost Rocks Formation are characterized by horizontal shortening with conjugate thrust faults and symmetric folds. PostPaleocene deformation includes strike-slip faulting in the southeastern part as well as in the Kodiak granite, which was previously described as completely undeformed. The main tectonic contact in the area is the Uganik Thrust, delimiting the Uyak Complex and the Kodiak Formation. The thrust consists of a meter-thick mylonitic zone of the hanging wall material (Uyak Complex), with significantly deformed foot wall (Kodiak Formation). Finally, extension can be observed in the Narrow Cape Formation, unconformably overlying the Ghost Rocks mélange in the SE margin of the belt. Such extension predates the very recent-to-present deformation, characterized by normal faulting and block tilting within the SE margin.

Preliminary results of Raman spectroscopy of carbonaceous material (RSCM) provide essential 
information as to the large-scale thermal structure of the accretionary prism. In the investigated profile, running from southeastern margin towards the northwest, the temperature does not increase monotonically towards the inner part of the wedge. Indeed, the highest temperatures (>300 ए) are found within the central part of the complex, in very thick turbiditic series accreted in a short period of time in the Paleocene. The thermal gap at the unconformity between the Ghost Rocks and Narrow Cape formations indicates fast uplift after accretion, followed by erosion, subsidence and sedimentation of Narrow Cape sediments. On the other side, no thermal gap is found around the Uganik Thrust like described at other OOST thrusts, which suggests that its activity predates exposure to the peak temperature. 